\title{
The impact of dipeptidyl peptidase 4 inhibition on incretin effect, glucose tolerance, and gastrointestinal-mediated glucose disposal in healthy subjects
}

\author{
N A Rhee ${ }^{1,2}$, S H Østoft ${ }^{1}$, J J Holst ${ }^{2}$, C F Deacon ${ }^{2}$, T VilsbølI ${ }^{1}$ and F K Knop ${ }^{1,2}$ \\ ${ }^{1}$ Center for Diabetes Research, Gentofte Hospital, University of Copenhagen, Niels Andersens Vej 65, \\ DK-2900 Hellerup, Denmark and ${ }^{2}$ Department of Biomedical Sciences, Faculty of Health and Medical Sciences, \\ The NNF Center for Basic Metabolic Research, University of Copenhagen, Copenhagen, Denmark
}

Correspondence should be addressed to F K Knop Email

filipknop@dadlnet.dk

\begin{abstract}
Objective: Inhibition of dipeptidyl peptidase 4 (DPP4) is thought to intensify the physiological effects of the incretin hormones. We investigated the effects of DPP4 inhibition on plasma levels of glucose-dependent insulinotropic polypeptide (GIP), glucagon-like peptide 1 (GLP1), incretin effect, glucose tolerance, gastrointestinal-mediated glucose disposal (GIGD) and gastric emptying in healthy subjects.

Design: A randomised, controlled and open-labelled study.

Methods: Ten healthy subjects (six women; age, $40 \pm 5$ years (mean \pm s.E.M.); BMI, $24 \pm 3 \mathrm{~kg} / \mathrm{m}^{2}$; fasting plasma glucose, $5.1 \pm 0.2 \mathrm{mmol} / \mathrm{l}$ and $\mathrm{HbA} 1 \mathrm{c}, 34 \pm 1 \mathrm{mmol} / \mathrm{mol}(5.3 \pm 0.1 \%)$ ) were randomised to two-paired study days comprising a $4-\mathrm{h} 50 \mathrm{~g}$ oral glucose tolerance test (OGTT) with paracetamol (A) and an isoglycaemic intravenous (i.v.) glucose infusion (B), with $\left(A_{1}+B_{1}\right)$ and without $\left(A_{2}+B_{2}\right)$ preceding administration of the DPP4 inhibitor sitagliptin.

Results: Isoglycaemia was obtained in all subjects on the paired study days. Significant increases in fasting levels and OGTT-induced responses of active GLP1 and GIP were seen after DPP4 inhibition. No significant impact of DPP4 inhibition on fasting plasma glucose $(5.1 \pm 0.1$ vs $4.9 \pm 0.1 \mathrm{mmol} / \mathrm{l}, P=0.3$ ), glucose tolerance (area under the curve (AUC) for plasma glucose, $151 \pm 35$ vs $137 \pm 26 \mathrm{mmol} / \mathrm{l} \times \mathrm{min}, P=0.7)$ or peak plasma glucose during OGTT $(8.5 \pm 0.4 \mathrm{vs} 8.1 \pm 0.3 \mathrm{mmol} / \mathrm{l}, P=0.3$ ) was observed. Neither incretin effect ( $40 \pm 9 \%$ (without DPP4 inhibitor) vs $40 \pm 7 \%$ (with DPP4 inhibitor), $P=1.0$ ), glucagon responses ( $1395 \pm 165$ vs $1223 \pm 195 \mathrm{pmol} / \mathrm{l} \times \mathrm{min}, P=0.41)$, GIGD $(52 \pm 4$ vs $56 \pm 5 \%, P=0.40)$ nor gastric emptying ( $T_{\max }$ for plasma paracetamol: $86 \pm 9$ vs $80 \pm 12 \mathrm{~min}, P=0.60$ ) changed following DPP4 inhibition.

Conclusions: These results suggest that acute increases in active incretin hormone levels do not affect glucose tolerance, GIGD, incretin effect, glucagon responses or gastric emptying in healthy subjects.
\end{abstract}

\section{Introduction}

In recent years, inhibitors of the ubiquitous enzyme dipeptidyl peptidase 4 (DPP4), which under normal circumstances degrades and thereby inactivates the insulinotropic gut incretin hormones, glucose-dependent insulinotropic polypeptide (GIP) and glucagon-like peptide 1 (GLP1), have been developed for the treatment of type 2 diabetes. GIP and GLP1 are secreted from enteroendocrine $\mathrm{K}$ and $\mathrm{L}$ cells, respectively, in response to meal ingestion (1). Following secretion, the glucosedependent insulinotropic activity of the hormones (neither hormone has insulinotropic activity at plasma glucose concentrations below $4 \mathrm{mmol} / \mathrm{l}$ ) is rapidly terminated by DPP4-induced degradation, resulting in plasma half-lives of 5-7 and 1-2 min for the active forms of GIP (c) 2014 European Society of Endocrinology Printed in Great Britain 
and GLP1 respectively. The incretin effect, defined as the increment in insulin release after an oral glucose load compared with i.v. glucose administered to copy the plasma glucose curve during the oral glucose load (isoglycaemic conditions), is thought to be dependent on the levels of active incretin hormones. Furthermore, the HbA1c-lowering effect of DPP4 inhibitors in type 2 diabetes is largely thought to be a result of the increased intact incretin hormone levels and their combined effects on the endocrine pancreas (insulinotropic and glucagonostatic effects) (2). The effects of the two hormones with respect to insulin secretion have been shown to be additive in humans (3), but, nevertheless, the role of the ratio between active hormones and their inactivated metabolites for the incretin effect remains to be established in healthy humans. Interestingly, several studies have evaluated the impact of DPP4 inhibition (using the DPP4 inhibitors sitagliptin or vildagliptin) on the incretin effect in type 2 diabetic subjects $(4,5,6)$ and found that the incretin effect did not change numerically (because insulin secretion increased, not only during oral glucose load but also after isoglycaemic intravenous (i.v.) glucose infusion (IIGI)) despite greater DPP4 inhibitor-mediated potentiation of active levels of incretin hormones during the oral glucose stimulus compared with the IIGI. Nevertheless, it is well-established that the insulinotropic effect of the incretin hormones is severely compromised in patients with type 2 diabetes, and these aforementioned findings may simply reflect reduced $\beta$ cell sensitivity to the insulinotropic effects of GIP and GLP1.

In this study, we investigated the impact of DPP4 inhibition on the incretin effect (by evaluating pancreatic hormone responses to oral glucose tolerance test (OGTT) and IIGI) in healthy normal-glucose tolerant subjects (in whom normal insulinotropic effects of the incretin hormones are expected). In addition, we studied the impact of DPP4 inhibitor-induced elevations of plasma levels of active incretin hormones on gastric emptying and gastrointestinal-mediated glucose disposal (GIGD).

\section{Subjects and methods}

\section{Ethical approval}

The study was approved by the Scientific Ethical Committee of the County of Copenhagen dated 17th August 2011 (journal number in the committee: H-1-2010-130) and registered with ClinicalTrials.gov (registration number: NCT01342939). The study conformed to the latest revision of the Declaration of Helsinki, and all subjects agreed to participate and gave oral and written consent.

\section{Subjects}

Ten healthy subjects participated in the study (anthropometric data in Table 1). They were all without family history of diabetes, exhibited normal fasting plasma glucose and HbA1c, and had a normal $75 \mathrm{~g}$ OGTT. All subjects were normal weight without hypertension or dyslipidaemia, and none were taking medicine on a regular basis. The subjects also participated as a control group in another study (7).

\section{Experimental procedures}

The participants were subjected to two-paired study days, comprising a 4-h $50 \mathrm{~g}$ OGTT (A) and an IIGI (B), respectively, with $\left(\mathrm{A}_{1}+\mathrm{B}_{1}\right)$ and without $\left(\mathrm{A}_{2}+\mathrm{B}_{2}\right)$ preceding open-label administration of the DPP4 inhibitor sitagliptin (100 mg 12 and $2 \mathrm{~h}$ before OGTT $\left(\mathrm{A}_{1}\right)$ and IIGI $\left(B_{1}\right)$ respectively; sitagliptin was administered twice in order to ensure maximum inhibition as the last administration was close to study start). The experimental days were performed in randomised order, although the 2 day As were performed before the 2 day Bs. On each day, experimental procedures were initiated in the morning after $10 \mathrm{~h}$ of fasting (including liquids and use of tobacco). The volunteers were asked not to perform physical exercise and to refrain from alcohol intake for 3 days before each experimental day.

On day $A_{1}$ (OGTT with DPP4 inhibition), a cannula was inserted into a cubital vein for sampling of arterialised blood (heated hand principle; using a heat pad $\left(45^{\circ} \mathrm{C}\right)$ wrapped around the hand and forearm). The participants were given $100 \mathrm{mg}$ of the DPP4 inhibitor sitagliptin twice, 12 and $2 \mathrm{~h}$ before start of the OGTT, which consisted of $50 \mathrm{~g}$ of water-free glucose dissolved in $300 \mathrm{ml}$ of water with $1.5 \mathrm{~g}$ of paracetamol (Panodil, GlaxoSmithKline Consumer Healthcare) ingested during $5 \mathrm{~min}$ (from 0 to $5 \mathrm{~min})$. Blood was drawn at $-15,-10,0,10,20,30,40$, $50,60,75,90,120,150,180$ and $240 \mathrm{~min}$ and distributed into chilled tubes containing ethylenediaminetetraacetic

Table 1 Anthropometric data of subjects. Values are mean \pm s.E.M. except for number of subjects and sex ratio.

\begin{tabular}{lcc}
\hline Parameter & Value \\
\hline Number of subjects & 10 \\
Sex ratio (female:male) & $6: 4$ \\
Age (years) & $40 \pm 5$ \\
BMl (kg/m $\left.{ }^{2}\right)$ & $24 \pm 3$ \\
Fasting plasma glucose (mmol/l) & $5.1 \pm 0.2$ \\
HbA1c (mmol/mol); HbA1c (\%) & $34 \pm 1 ; 5.3 \pm 0.1$ \\
\hline
\end{tabular}


acid (EDTA) and DPP4 inhibitor (valine-pyrrolidide, $0.01 \mathrm{mmol} / 1$ final concentration; a gift from Novo Nordisk, Bagsværd, Denmark) for the analyses of glucagon, GLP1 and GIP. Blood for analysis of serum insulin and C-peptide was collected into dry tubes for coagulation (20 min at room temperature) and blood for the analysis of paracetamol was collected in chilled tubes containing heparin. All tubes were immediately cooled on ice and thereafter centrifuged $(1200 \mathrm{~g})$ for $20 \mathrm{~min}$ at $4{ }^{\circ} \mathrm{C}$. Plasma was stored at $-20{ }^{\circ} \mathrm{C}$ until analysis. For bedside measurement of plasma glucose, $0.2 \mathrm{ml}$ blood was added to fluoride tubes and centrifuged $(10000 \mathrm{~g})$ immediately for $45 \mathrm{~s}$ at room temperature.

On day $B_{1}$ (IIGI with DPP4 inhibition), the subjects were given $100 \mathrm{mg}$ of the DPP4 inhibitor sitagliptin twice, 12 and $2 \mathrm{~h}$ before start of the IIGI. Cannulas were inserted into the cubital vein of each arm, one for sampling of arterialised blood and one for infusion of glucose. An adjustable i.v. glucose infusion $(20 \% \mathrm{w} / \mathrm{v})$ was performed, aiming at duplicating the plasma glucose profile determined in the same individual on day $\mathrm{A}_{1}$. Blood was sampled as on day $A_{1}$.

Day $A_{2}$ (OGTT without DPP4 inhibition) and day $B_{2}$ (IIGI without DPP4 inhibition) were similar to day $\mathrm{A}_{1}$ and day $B_{1}$, respectively, except that the subjects did not receive sitagliptin.

\section{Analyses}

During experiments, plasma glucose concentrations were measured using a glucose analyzer (Yellow Springs Instrument YSI 2300 STAT plus analyzer, YSI, Inc., Yellow Springs, OH, USA). Serum insulin and C-peptide concentrations were measured using two-sided electrochemiluminescence immunoassay (Siemens Healthcare, Ballerup, Denmark) and plasma paracetamol was measured using the Vitros ACET slide method (Ortho Clinical Diagnostics, Johnson \& Johsnon, Birkerød, Denmark) as described elsewhere $(8,9)$. Plasma concentrations of total GLP1 and GIP were measured by RIAs as previously described $(10,11)$. Intact GIP was measured using antibody code no. 98171 as previously described (12). Intact GLP1 was measured using an ELISA assay. The assay is a two-site sandwich assay using two MABs: GLP1F5 as catching antibody (C-terminally directed) and Mab26.1 as detecting antibody (N-terminally directed) (13). The glucagon assay is directed against the C-terminal of the glucagon molecule and measures glucagon of pancreatic origin (14). For the GIP, GLP1 and glucagon assays, plasma samples (EDTA) were extracted using ethanol ( 70\%) before assay to eliminate unspecific interference. Sensitivity is $<2 \mathrm{pmol} / \mathrm{l}$, with intra-assay coefficient of variation $(\mathrm{CV})$ being $<6 \%$ and inter-assay $\mathrm{CV}$ being $<15 \%$ in these assays.

\section{Calculations and statistical analyses}

AUCs were calculated using the trapezoid rule, with incremental AUCs being calculated after baseline subtraction. Insulin secretion rate (ISR) was calculated using a two-compartment model of C-peptide kinetics and population-based C-peptide kinetic parameters (15), and is expressed as picomoles insulin secreted per minute per kilogram of body weight. Incretin effects were calculated by relating the difference in integrated $\beta$ cell secretory responses (AUC for insulin, C-peptide and ISR respectively) between stimulation with OGTT and corresponding IIGI to the response after OGTT (incretin effect (\%)= $\left.100 \% \times\left(\mathrm{AUC}_{\mathrm{OGTT}}-\mathrm{AUC}_{\mathrm{IIGI}}\right) / \mathrm{AUC} \mathrm{C}_{\mathrm{OGTT}}\right)$ (16). GIGD was calculated by relating the difference in glucose administered at OGTT and IIGI to the amount of glucose administered during OGTT (GIGD (\%)=100\% $\times$ (glucose $_{\text {OGTT }}-$ glucose $_{\text {IIGI }}$ /glucose oGTT $_{\text {glu }}$ (17). All results are expressed as mean \pm s.E.M. unless otherwise stated. Bartlett's test was used to test for normal distribution. Comparisons of experiments in which the data were distributed normally were made with two-tailed $t$-test. For data that did not follow a normal distribution, the significance of differences between groups was tested using Mann-Whitney $U$ test, and for within-group comparisons, the Wilcoxon's signed-rank test for paired differences was used. As post hoc analysis, Bonferroni adjustments were used. One-sample $t$-test (two-tailed) was used to test for significant incretin effects (different from 0). Differences with $P$ values $<0.05$ were considered significant.

\section{Results}

\section{Plasma glucose, glucose infusions and GIGD}

Fasting plasma glucose levels were similar on all study days $\left(4.9 \pm 0.1\left(\mathrm{~A}_{1}\right), 5.0 \pm 0.1\left(\mathrm{~B}_{1}\right), 5.1 \pm 0.1\left(\mathrm{~A}_{2}\right)\right.$ and $5.0 \pm$ $\left.0.1 \mathrm{mmol} / 1\left(\mathrm{~B}_{2}\right), 0.31 \leq P \leq 0.87\right)$. Isoglycaemic conditions during oral and i.v. glucose administration were achieved with and without DPP4 inhibition (Fig. 1). Administration of the DPP4 inhibitor had no significant effect on plasma glucose profiles $(P=0.53$ ) or glucose tolerance (measured as AUC $(1339 \pm 35$ with DPP4 inhibitor vs $1351 \pm$ $18 \mathrm{mmol} / 1 \times \min$ without, $P=0.67)$ and incremental AUC $(151 \pm 35$ with vs $138 \pm 26 \mathrm{mmol} / 1 \times$ min without, 

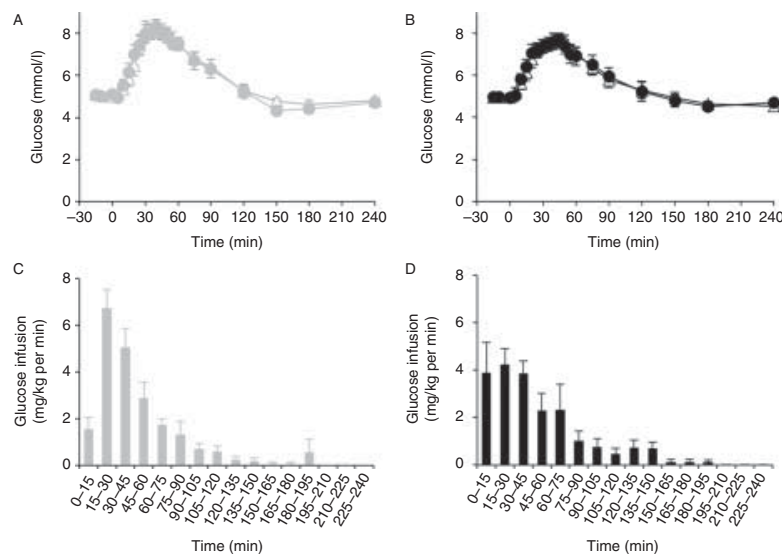

Figure 1

Plasma glucose levels and glucose infusion rates. Plasma concentrations of glucose (A and B) and glucose amounts infused every 15 min (C and D) without DPP4 inhibition (left panel) and with DPP4 inhibition (right panel) after stimulation with $50 \mathrm{~g}$ OGTT (solid circles) and isoglycaemic i.v. glucose (open triangles).

$P=0.52)$ ) during OGTT. Glucose amounts infused during 15-min intervals are shown in Fig. 1. No statistically significant differences in 15-min interval glucose infusion rates between days $B_{1}$ and $B_{2}$ were observed, or in overall amounts of glucose needed to copy the $50 \mathrm{~g}$ OGTT plasma glucose curves during the two IIGI days with and without DPP4 inhibition ( $22 \pm 2$ vs $24 \pm 2$ g, $P=0.40$ ) respectively. Consequently, GIGD was similar with and without DPP4 inhibition ( $56 \pm 5$ vs $52 \pm 4 \%, P=0.4$ ).

\section{Incretin hormones}

Time courses for total and intact incretin levels are plotted in Fig. 2, and integrated levels are listed in Table 2. DPP4 inhibition had no impact on mean fasting levels of total GIP (18 \pm 6 with DPP4 inhibition vs $12 \pm 3 \mathrm{pmol} / 1$ without, $P=0.44)$ or intact GIP ( $17 \pm 1$ vs $13 \pm 1 \mathrm{pmol} / \mathrm{l}, P=0.12)$. DPP4 inhibitor administration resulted in significantly larger intact GIP response to OGTT (71 and 158\% when evaluated from AUC and incremental AUC respectively) and a near-significant $62 \%$ decrease in the total GIP response (incremental AUC) to OGTT $(P=0.06)$. Neither intact nor total GIP levels changed during IIGI, and this was not altered significantly by DPP4 inhibition. Mean fasting levels of intact GLP1 were significantly higher with DPP4 inhibition ( $4 \pm 1 \mathrm{pmol} / \mathrm{l}$ (days $\mathrm{A}_{1}$ and $\mathrm{B}_{1}$ ) vs $2 \pm 0.5 \mathrm{pmol} / 1$ (days $\mathrm{A}_{2}$ and $\mathrm{B}_{2}$ ), $P<0.01$ ), whereas fasting levels of total
GLP1 were similar $(P=0.14)$ with $\left(10 \pm 1 \mathrm{pmol} / 1\right.$ (days $A_{1}$ and $\left.B_{1}\right)$ ) and without DPP4 inhibition ( $8 \pm 1 \mathrm{pmol} / \mathrm{l}$ (days $\mathrm{A}_{2}$ and $\left.\mathrm{B}_{2}\right)$ ). During DPP4 inhibition, we found a significant $67 \%$ increase in the intact GLP1 response (AUC) to OGTT and a significant $149 \%$ increase in the AUC for intact GLP1 during IIGI. There was a significant 30\% decrease in total GLP1 levels after administration of DPP4 inhibitor on the IIGI days and an insignificant $(P=0.13) 10 \%$ decrease on OGTT days (as evaluated from AUCs). The response of total GLP1 to DPP4 inhibition during OGTT was decreased by $46 \%(P=0.10)$, being measured as incremental AUC.

\section{Insulin, C-peptide, ISR and incretin effect}

Time courses for insulin, C-peptide and ISR are illustrated in Fig. 3. AUCs are listed in Table 3. Mean fasting levels of
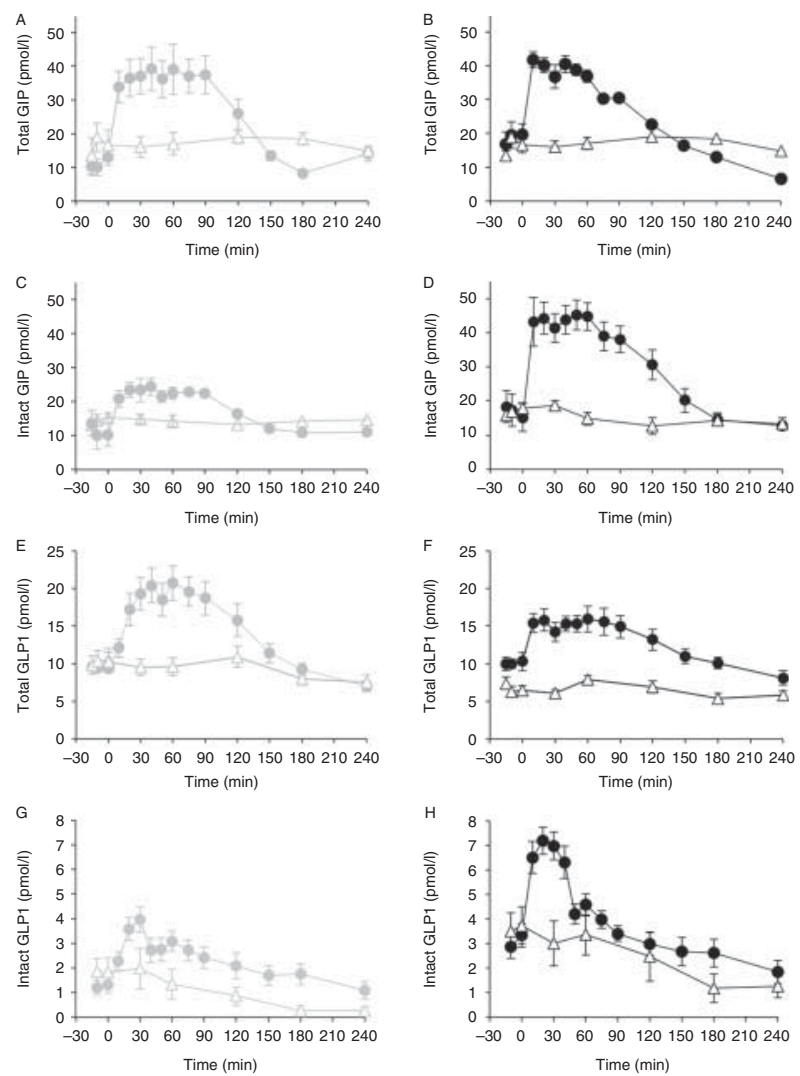

Figure 2

Incretin hormone levels. Plasma concentrations of total and intact glucose-dependent insulinotropic polypeptide (GIP; A, B, $C$ and D) and GLP1 (E, F, G and H) during $50 \mathrm{~g}$ OGTT (solid circles) and isoglycaemic i.v. glucose infusion (open triangles) without DPP4 inhibitor (left panel, grey curves) and with DPP4 inhibitor (right panel, black curves). 
Table 2 Integrated levels of incretin hormones' responses.

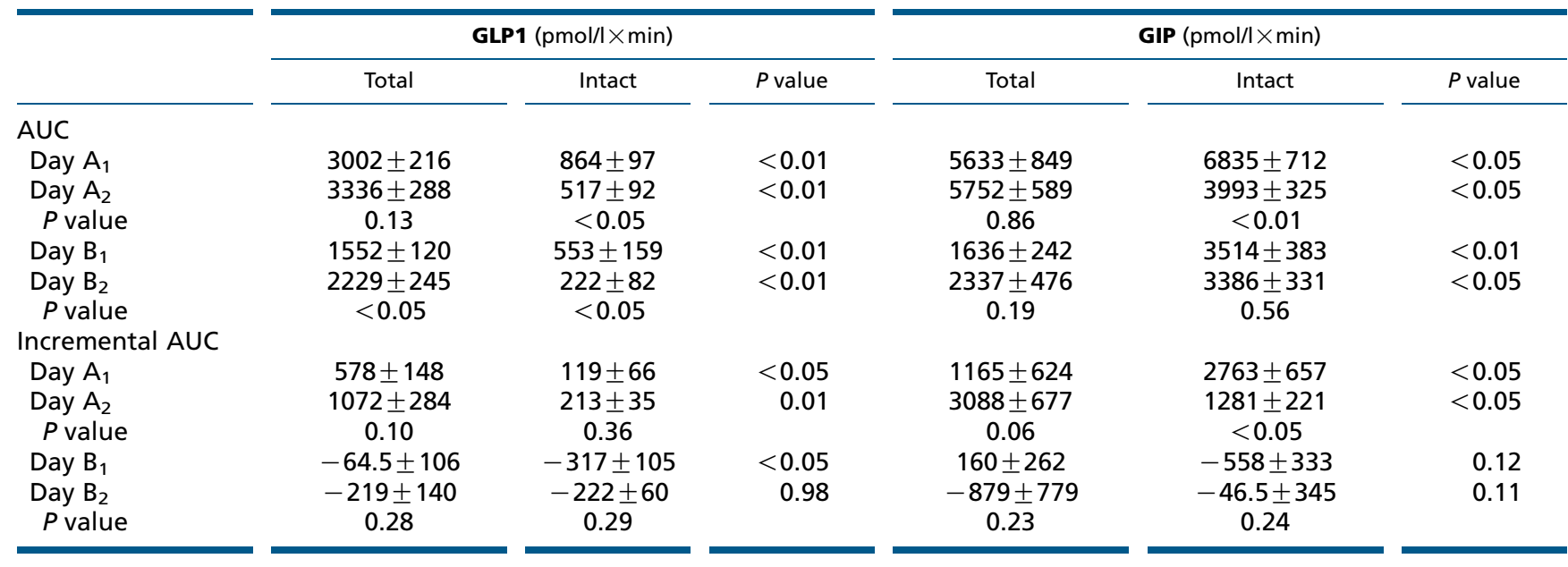

Responses of total and intact GLP1 and GIP measured as AUC (total AUC) and incremental AUC during days $\mathrm{A}_{1}$ and $\mathrm{A}_{2}$ (OGTT with and without DPP4 inhibitor respectively) and during days $B_{1}$ and $B_{2}$ (isoglycaemic i.v. glucose infusion with and without DPP4 inhibitor respectively).

insulin were similar with and without DPP4 inhibition (55 \pm 7 (days $A_{1}$ and $B_{1}$ ) vs $61 \pm 8$ pmol/l (days $A_{2}$ and $B_{2}$ ), $P=0.53$ ). No difference was observed in C-peptide fasting levels either ( $436 \pm 35$ (days $A_{1}$ and $B_{1}$ ) vs $439 \pm 30$ (days $A_{2}$ and $\left.\mathrm{B}_{2}\right), P=0.93$ ). Regardless of DPP4 inhibition, OGTT responses (AUCs) were consistently and significantly higher than IIGI responses for insulin, C-peptide and ISR. Administration of the DPP4 inhibitor did not influence any of these parameters significantly. However, according to 2-factor repeated measures analysis of variance and post hoc testing, DPP4 inhibitor (vs without) caused higher insulin levels at time point 10, 40, 50, 60, 75 and $240 \mathrm{~min}$. As noted in Table 3, incretin effect values varied between 30 and $40 \%$, depending on which $\beta$ cell secretory parameter the calculation was based on, but were unaffected by DPP4 inhibition.

\section{Glucagon}

Time courses for plasma concentrations of glucagon during OGTTs and IIGIs are illustrated in Fig. 4. Fasting plasma glucagon concentrations were similar on all 4 study days. DPP4 inhibition had no impact on glucagon responses during OGTT, according to AUCs $(1223 \pm 195$ with vs $1395 \pm 165 \mathrm{pmol} / \mathrm{l} \times \mathrm{min}$ without DPP4 inhibitor, $P=0.41)$ or incremental AUCs for glucagon $(-825 \pm 229$ with vs $-517 \pm 193 \mathrm{pmol} / 1 \times$ min without DPP4 inhibitor, $P=0.25)$. Neither did DPP4 inhibition influence glucagon responses to IIGI (AUCs, $1137 \pm 168$ with vs $1131 \pm 142 \mathrm{pmol} / 1 \times \min$ without DPP4 inhibitor, $P=0.79$ and incremental AUCs, $-632 \pm 222$ with vs $-830 \pm 251 \mathrm{pmol} / 1 \times \min$ without DPP4 inhibitor, $P=0.56)$. No significant differences between glucagon responses to OGTT and IIGI (with or without DPP4 inhibition) were observed.
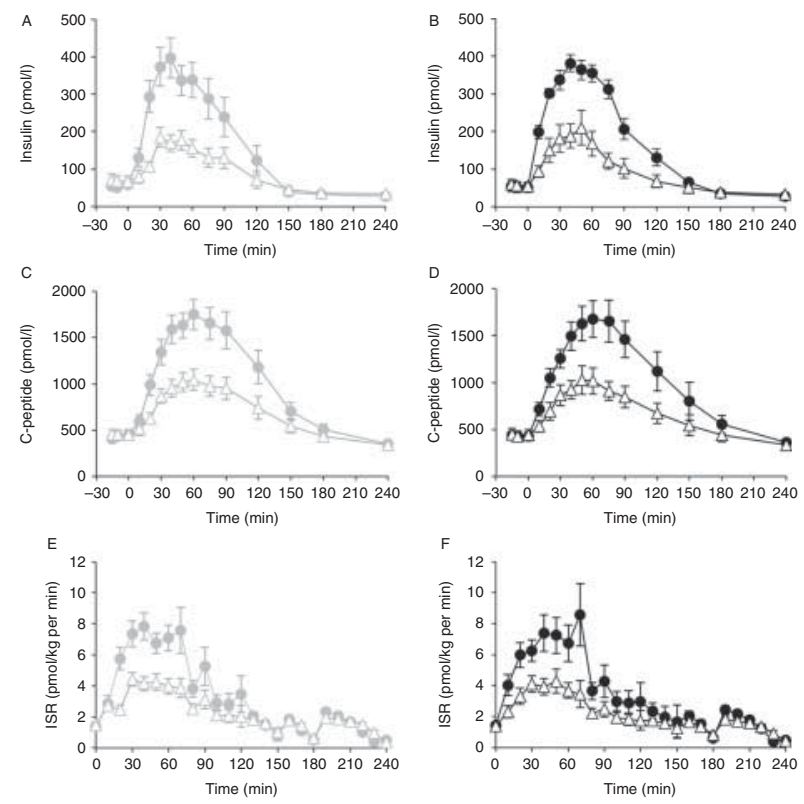

\section{Figure 3}

Plasma insulin ( $A$ and $B$ ), C-peptide (C and D) and insulin secretion rates (ISR; $E$ and F). Time courses of plasma insulin, C-peptide and ISR during $50 \mathrm{~g}$ OGTT (solid circles) and isoglycaemic i.v. glucose infusion (open triangles) without DPP4 inhibitor (left panel, grey curves) and with DPP4 inhibitor (right panel, black curves). 
Table $3 \beta$ cell secretory responses and incretin effects. Values are expressed as mean \pm s.E.M.

\begin{tabular}{l} 
Parameter \\
\hline AUC-Insulin $(\mathrm{mU} / / \times \mathrm{min})$ \\
No DPP4 inhibition \\
DPP4 inhibition \\
$P$ value \\
AUC-C-peptide $(\mathrm{nmol} / \mathrm{I} \times \mathrm{min})$ \\
No DPP4 inhibition \\
DPP4 inhibition \\
$P$ value \\
AUC-ISR (pmol/kg) \\
No DPP4 inhibition \\
DPP4 inhibition \\
$P$ value
\end{tabular}

\begin{tabular}{c}
\hline OGTT \\
\hline $2538 \pm 322$ \\
$2650 \pm 502$ \\
0.71 \\
$235 \pm 20$ \\
$236 \pm 28$ \\
1.00 \\
$797 \pm 75$ \\
$821 \pm 119$ \\
0.77
\end{tabular}

\begin{tabular}{c}
\hline IIGI \\
\hline $1422 \pm 211$ \\
$1456 \pm 228$ \\
0.84 \\
$160 \pm 17$ \\
$154 \pm 19$ \\
0.73 \\
$548 \pm 60$ \\
$522 \pm 62$ \\
0.80
\end{tabular}

\begin{tabular}{c}
\hline Difference \\
\hline $1116 \pm 302$ \\
$1194 \pm 394$ \\
0.13 \\
$76 \pm 17$ \\
$81 \pm 18$ \\
0.27 \\
$248 \pm 63$ \\
$299 \pm 74$ \\
0.37
\end{tabular}

\begin{tabular}{c}
\hline P value \\
\hline 0.01 \\
0.01 \\
\\
\\
$<0.01$ \\
$<0.01$ \\
\\
$<0.01$ \\
$<0.01$
\end{tabular}

Incretin effect $(\%)$

$\| G I$, isoglycaemic i.v. glucose infusion.

\section{Gastric emptying}

Rate of gastric emptying as measured by AUC for paracetamol was unaltered after DPP4 inhibition $(17 \pm 2$ with vs $17 \pm 2 \mathrm{pmol} / \mathrm{l} \times \mathrm{min}$ without DPP4 inhibition, $P=0.80$, Fig. 5). Similarly, peak concentration $(99 \pm 1$ with vs $104 \pm 8 \mathrm{nmol} / 1$ without DPP4 inhibitor, $P=0.35$ ) and peak concentration time for paracetamol were unaltered $(80 \pm 12$ with vs $86 \pm 9$ min without DPP4 inhibitor, $P=0.60$ ) by DPP4 inhibition.

\section{Discussion}

We show that elevated plasma levels of intact active incretin hormones (attained through 'acute' inhibition of DPP4) have no effect on incretin effect, fasting plasma glucose, glucose tolerance, GIGD, glucagon responses to oral or i.v. glucose or gastric emptying following OGTT in healthy subjects.

This study was conducted in young healthy adults of both genders. The participants were normal-glucose tolerant with normal fasting plasma glucose levels and without any predisposition to diabetes. Thus, their $\beta$ cells would be expected to be fully sensitive to any increment in intact levels of the incretin hormones. This in combination with the well-established and powerful insulinotropic effect of intact incretin hormones led us to propose a hypothesis that DPP4 inhibition during OGTT and IIGI would potentiate the incretin effect in healthy subjects. Though widely used in the treatment of type 2 diabetes, the effect of DPP4 inhibition on the incretin effect has, to our knowledge, not been described in healthy subjects. The combined $4 \mathrm{~h}$-OGTT and IIGI is a standardised way of measuring the incretin effect.
In this study, we did not measure the concentration of sitagliptin or the activity of DPP4, but assumed that the acute administration of the DPP4 inhibitor at its therapeutic dose would inactivate the enzyme by $80-96 \%$ in the plasma, as shown previously (18), and allow plasma levels of intact incretin hormones to increase (19). This assumption was supported by the significantly elevated responses of intact GIP and GLP1 during OGTT experiments with preceding administration of DPP4 inhibitor.

We included ten subjects in this study. According to our power calculations, this number of subjects would allow us to detect a $9 \%$ change in incretin effect with $80 \%$ probability. Given the very small and insignificant differences in incretin effect between examinations with and without DPP4 inhibition, it is unlikely that inclusion of more subjects would have revealed clinically relevant differences. However, it is possible that inclusion of more subjects would have resulted in statistical significance of
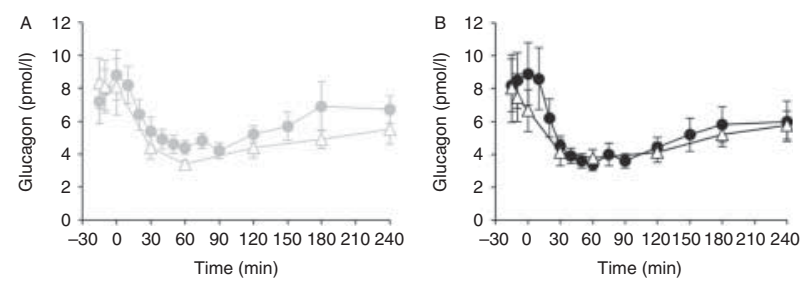

\section{Figure 4}

Plasma glucagon. Concentrations of plasma glucagon during $50 \mathrm{~g}$ OGTT (solid circles) and isoglycaemic i.v. glucose infusion (open triangles) without DPP4 inhibitor (A, grey curves) and with DPP4 inhibitor (B, black curves). 


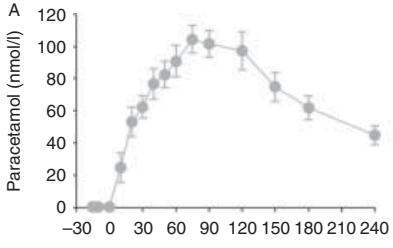

Time ( $\mathrm{min})$

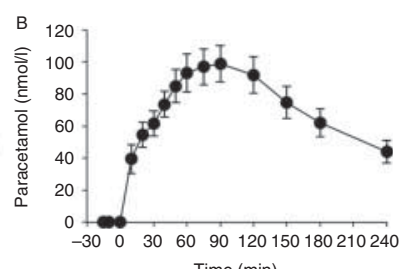

Time (min)

\section{Figure 5}

Gastric emptying. Concentrations of plasma paracetamol during $50 \mathrm{~g}$ OGTT with $1 \mathrm{~g}$ paracetamol without DPP4 inhibitor (A, grey curves) and with DPP4 inhibitor (B, black curves).

the relatively small numeric differences in our secondary end-points (glucose tolerance and insulin and glucagon responses; see below).

Few studies describe the effects of DPP4 inhibition on incretin levels in healthy subjects. El-Ouaghlidi et al. (20) found significant 48 and $21 \%$ reductions in total GLP1 and GIP, respectively (measured as incremental AUC), after acute administration of $100 \mathrm{mg}$ vildagliptin in 16 male subjects undergoing a $75 \mathrm{~g}$ OGTT after an overnight fast, with a similar effect being observed after a meal test in non-diabetic subjects given $100 \mathrm{mg}$ sitagliptin (21). These results are thus in agreement with findings in experimental animals (22), where increased levels of active hormones seemed to inhibit incretin secretion in a negative feed-back loop. Migoya et al. (23) reported approximately twofold higher levels of intact GLP1 and GIP after acute (2 days') administration of sitagliptin, with similar effects on GLP1 being reported by Hu et al. (24) after a 10-day period with once daily ingestion of $100 \mathrm{mg}$ vildagliptin in ten healthy subjects (GIP and incretin effect were not measured). In contrast to the relatively sparse data on the impact of DPP4 inhibition on glucose metabolism and incretin levels in healthy subjects, the 'acute' effect of DPP4 inhibition in type 2 diabetes has been studied in more detail. Herman et al. (19) subjected 58 participants with type 2 diabetes (mean age, 50 years and mean BMI, $29.5 \mathrm{~kg} / \mathrm{m}^{2}$ ) to a $75 \mathrm{~g}$ OGTT $2 \mathrm{~h}$ after oral administration of either 25 or $200 \mathrm{mg}$ of sitagliptin and found significant reductions in incremental AUCs for plasma glucose by $22 \%$ (25 mg) and 26\% (200 mg), respectively, compared with placebo. This concurs with the results obtained by Vardarli et al. who subjected 21 patients with type 2 diabetes to a $75 \mathrm{~g}$ OGTT (and an IIGI) after 13 days of treatment with $100 \mathrm{mg}$ of the DPP4 inhibitor vildagliptin. This resulted in a near-significant improvement in glucose tolerance measured as incremental AUC for plasma glucose during the OGTT.
Others have since then corroborated these results $(5,6)$. In a study by Bock et al. (25), 22 subjects with impaired fasting glucose were subjected to a meal test before and after 8 weeks of $100 \mathrm{mg}$ sitagliptin once daily. Fasting or postprandial glucose, insulin or C-peptide concentrations were not altered in spite of increased levels of intact GLP1 (and decreased total levels). Rosenstock et al. (26) treated subjects with impaired glucose tolerance with vildagliptin and found increased levels of active GLP1, which associated with postprandial suppression of glucagon and increased ISR.

In our study, DPP4 inhibition reduced incremental AUC for glucose insignificantly by only $9 \%$ compared with no DPP4 inhibition, incremental AUC for insulin was only increased insignificantly by $8 \%$ compared with no DPP4 inhibition, and C-peptide levels and ISRs were unaltered (despite significantly increased amounts of active levels of both GIP and GLP1). This is in agreement with data reported by Ohlsson et al. (27), where acute administration of sitagliptin in healthy lean men increased intact GLP1 levels and resulted in lower glycaemic excursions following glucose, fat or protein ingestion without any significant changes in pancreatic endocrine responses. Aoki et al. (28) have shown similar results for both sitagliptin as well as vildagliptin (29), and a recent study by Wu et al. (30) has supported these findings. It is wellknown that the insulinotropic effects of the incretin hormones are strictly glucose dependent; i.e. increase with higher plasma glucose levels. In line with this, Herman et al. further found a significant increase in incremental AUC for insulin during OGTT of $21 \%(25 \mathrm{mg})$ and $22 \%(200 \mathrm{mg})$, respectively, in patients with type 2 diabetes. Likewise, Vardarli et al. found a significant increase in C-peptide both after OGTT and IIGI as a result of DPP4 inhibition in their patients with type 2 diabetes, i.e. the diabetic individuals increased insulin secretion by $\sim 30 \%$ after OGTT and IIGI from a baseline that was already rather high compared with what is normally seen in healthy subjects (most likely due to insulin resistanceinduced compensatory insulin secretion). This increase in endogenous insulin production following administration of sitagliptin in subjects with type 2 diabetes was demonstrated again in 2014 (5). The glucose-dependent insulinotropic effects of the incretin hormones and the high plasma glucose concentrations of the patients with type 2 diabetes studied by Herman et al. and by Vardarli et al., respectively, may explain the greater impact of DPP4 inhibition on glucose tolerance in these studies. However, it is at variance with the otherwise well-established notion that patients with type 2 diabetes are characterised by a 
severely compromised insulinotropic effect of GIP and a decreased insulinotropic potency of GLP1 compared with normal-glucose tolerant subjects. This, combined with the insulin resistance associated with type 2 diabetes, has led to the hypothesis that reduction in glucagon levels (exerted by increased active GLP1 levels) constitutes a major glucose-lowering mechanism of DPP4 inhibition in type 2 diabetes (31). Interestingly, in this study in healthy individuals, glucagon levels were unaltered by DPP4 inhibition (and increased levels of active incretin hormones), as also seen in other studies with DPP4 inhibition in non-diabetic subjects (27). This is in contrast to studies in patients with type 2 diabetes, in whom DPP4 inhibition leads to decreased glucagon levels (4). This discrepancy between healthy subjects and patients with type 2 diabetes might be explained by several things. First, like the insulinotropic effect of GLP1, the glucagon-suppressive effect of this incretin hormone has been shown to be glucose dependent (most pronounced during high plasma glucose concentrations), and in contrast to the insulinotropic effect of GLP1, the glucagonostatic effect is preserved in patients with type 2 diabetes (32). Second, patients with type 2 diabetes are typically characterised by hyperglucagonaemia and, thus, a larger potential for any glucagonsuppressive effect to become apparent. Lastly, it has been shown that GIP exerts glucose-dependent glucagonotropic effects, which are most pronounced during low plasma glucose concentrations (33). Thus, the relatively low plasma glucose levels in the healthy subjects participating in this study may favour a counterbalanced effect of the two incretin hormones on glucagon secretion.

The incretin hormones mediate the incretin effect. It is therefore surprising that increasing the amount of active incretin hormones did not affect the incretin effect, in any of the three studies in patients with type 2 diabetes $(4,5,6)$, nor in our healthy subjects. Vardarli et al. observed higher levels of insulin secretion during both the OGTT and the IIGI with DPP4 inhibition (vs IIGI without DPP4 inhibition), whereby the incretin effect, as calculated by relating the responses to the OGTT and IIGI, remained unchanged. By the use of mathematical modelling, Muscelli et al. attributed the lack of change in the incretin effect after administration of sitagliptin to an improvement in $\beta$ cell sensitivity to glucose during both oral and i.v. glucose challenges following DPP4 inhibition. The lack of DPP4 inhibitor-induced insulin enhancement during OGTT (which would have created an increasing incretin effect) in our healthy subjects does not conform to the present understanding of incretin physiology. As mentioned above, DPP4 inhibitors are thought to potentiate glucose-stimulated insulin secretion via increased amounts of circulating active GLP1 and GIP. Physiological levels of both hormones (similar to the levels of intact hormones attained in the present study) have been shown to exert strong insulinotropic effects in healthy subjects already during rather low plasma glucose concentrations (similar to and even lower than the glucose levels attained in our subjects) (34). Therefore, it is surprising that the significantly increased levels of intact active forms of GIP and GLP1 in this study did not translate into potentiation of the incretin effect. Thus, it seems that increased levels of active incretin hormones in healthy individuals do not influence the incretin effect per se and that the incretin effect in healthy subjects is influenced by mechanisms other than active GIP and GLP1 levels alone. It might surprise that inhibiting degradation of GLP1 by administrating a DPP4 inhibitor results in reduced levels of total GLP1. These lower levels of total GLP1 after administration of the DPP4 inhibitor imply a negative feedback of intact GLP1 on the secretory mechanisms of the L cells, possibly through somatostatin as indicated from in vitro studies $(35,36)$. Although not statistically significant, the reduction in the response of total GLP1 during OGTT (10\% when evaluated from AUC $(P=0.13)$ and $46 \%$ when evaluated from incremental AUC $(P=0.10))$ with DPP4 inhibition in our study was in line with what has been previously described (22). Similarly, the response of total GIP tended to be decreased during OGTT with preceding DPP4 inhibitor administration (when evaluated from incremental AUC, $P=0.06$ ). Generally, administration of DPP4 inhibitor increased baseline levels of intact GLP1 but not intact GIP. Thus, one explanation for the lack of increase in incretin effect could be that the increase in intact GLP1 levels due to DPP4 inhibition results in reduced secretion of GLP1. In this way stimulation of vagal afferents in the intestinal mucosa may have been weakened following DPP4 inhibitor administration. As suggested by Plamboeck et al. (37), compromised vagal transmission of GLP1 signals may contribute to reduce peripheral GLP1 effect including the incretin effect.

In conclusion, DPP4 inhibitor-induced doubling of circulating levels of intact active GLP1 and GIP levels did not influence incretin effect, GIGD or glucagon responses to oral and i.v. glucose in healthy subjects. Clearly, further studies are needed to obtain a clear picture of the mechanisms linking incretin hormone secretion, circulating levels of GLP1 and GIP and secretion of insulin and glucagon. 


\section{Declaration of interest}

The authors declare that there is no conflict of interest that could be perceived as prejudicing the impartiality of the research reported.

Funding

This study was funded by an unrestricted grant from the Novo Nordisk Foundation.

\section{Author contribution statement}

N A Rhee planned the study, performed the study days and authored the first draft of the manuscript. S H Østoft planned the study, performed the study days and reviewed the manuscript. J J Holst analysed blood samples and reviewed the manuscript. T Vilsbøll participated in the planning of the study and reviewed the manuscript. F K Knop designed and planned the study and reviewed the manuscript.

\section{Acknowledgements}

The authors are grateful to our volunteers whose availability made this work possible and to $\mathrm{N}$ Kjeldsen, J Purtoft and L Albæk for technical assistance.

\section{References}

1 Ørskov C, Wettergren A \& Holst JJ. Secretion of the incretin hormones glucagon-like peptide- 1 and gastric inhibitory polypeptide correlates with insulin secretion in normal man throughout the day. Scandinavian Journal of Gasteroenterology 199631 665-670. (doi:10.3109/ 00365529609009147)

2 Deacon CF, Hughes TE \& Holst JJ. Dipeptidyl peptidase IV inhibition potentiates the insulinotropic effect of glucagon-like peptide 1 in the anesthetized pig. Diabetes 199847 764-769. (doi:10.2337/diabetes.47. 5.764)

3 Nauck MA, Bartels E, Ørskov C, Ebert R \& Creutzfeldt W. Additive insulinotropic effects of exogenous synthetic human gastric inhibitory polypeptide and glucagon-like peptide-1-(7-36) amide infused at nearphysiological insulinotropic hormone and glucose concentrations. Journal of Clinical Endocrinology and Metabolism 199376 912-917. (doi:10.1210/jcem.76.4.8473405)

4 Vardarli I, Nauck MA, Köthe LD, Deacon CF, Holst JJ, Schweizer A \& Foley JE. Inhibition of DPP-4 with vildagliptin improved insulin secretion in response to oral as well as "isoglycemic" intravenous glucose without numerically changing the incretin effect in patients with type 2 diabetes. Journal of Clinical Endocrinology and Metabolism 201196 945-954. (doi:10.1210/jc.2010-2178)

5 Vardarli I, Arndt E, Deacon CF, Holst JJ \& Nauck MA. Effects of sitagliptin and metformin treatment on incretin hormone and insulin secretory responses to oral and "isoglycemic" intravenous glucose. Diabetes 201463 663-674. (doi:10.2337/db13-0805)

6 Muscelli E, Casolaro A, Gastaldelli A, Mari A, Seghieri G, Astiarraga B, Chen Y, Alba M, Holst J \& Ferrannini E. Mechanisms for the antihyperglycemic effect of sitagliptin in patients with type 2 diabetes. Journal of Clinical Endocrinology and Metabolism 201297 2818-2826. (doi:10.1210/jc.2012-1205)

7 Østoft SH, Bagger JI, Hansen T, Pedersen O, Holst JJ, Knop FK \& Vilsbøll T. Incretin effect and glucagon responses to oral and intravenous glucose in patients with maturity onset diabetes of the young - type 2 and type 3. Diabetes 2014. In Press. (doi:10.2337/ db13-1878)
8 Miceli JN, Aravind MK, Cohen SN \& Done AK. Simultaneous measurements of acetaminophen and salicylate in plasma by liquid chromatography. Clinical Chemistry 197925 1002-1004.

9 Medhus AW, Lofthus CM, Bredesen J \& Husebye E. Gastric emptying: the validity of the paracetamol absorption test adjusted for individual pharmacokinetics. Neurogastroenterology and Motility 200113 179-185. (doi:10.1046/j.1365-2982.2001.00249.x)

10 Ørskov C, Rabenhøj L, Wettergren A, Kofod H \& Holst JJ. Tissue and plasma concentrations of amidated and glycine-extended glucagonlike peptide I in humans. Diabetes 199443 535-539. (doi:10.2337/diab. 43.4.535)

11 Krarup T \& Holst JJ. The heterogeneity of gastric inhibitory polypeptide in porcine and human gastrointestinal mucosa evaluated with five different antisera. Regulatory Peptides 19849 35-46. (doi:10.1016/ 0167-0115(84)90005-3)

12 Deacon CF, Nauck MA, Meier J, Hucking K \& Holst JJ. Degradation of endogenous and exogenous gastric inhibitory polypeptide in healthy and in type 2 diabetic subjects as revealed using a new assay for the intact peptide. Journal of Clinical Endocrinology and Metabolism 200085 3575-3581. (doi:10.1210/jcem.85.10.6855)

13 Wilken M, Larsen F, Buckley D \& Holst J. New highly specific immunoassays for glucagon-like peptide-1 (GLP-1) (Abstract). Diabetologia 199942 (Suppl 1) A196.

14 Ørskov C, Jeppesen J, Madsbad S \& Holst JJ. Proglucagon products in plasma of noninsulin-dependent diabetics and nondiabetic controls in the fasting state and after oral glucose and intravenous arginine. Journal of Clinical Investigation 199187 415-423. (doi:10.1172/ JCI115012)

15 Van Cauter E, Mestrez F, Sturis J \& Polonsky KS. Estimation of insulin secretion rates from C-peptide levels. Comparison of individual and standard kinetic parameters for C-peptide clearance. Diabetes 199241 368-377. (doi:10.2337/diabetes.41.3.368)

16 Nauck MA, Homberger E, Siegel EG, Allen RC, Eaton RP, Ebert R \& Creutzfeldt W. Incretin effects of increasing glucose loads in man calculated from venous insulin and C-peptide responses. Journal of Clinical Endocrinology and Metabolism 198663 492-498. (doi:10.1210/ jcem-63-2-492)

17 Hare KJ, Vilsbøll T, Holst JJ \& Knop FK. Inappropriate glucagon response after oral compared with isoglycemic intravenous glucose administration in patients with type 1 diabetes. American Journal of Physiology. Endocrinology and Metabolism 2010298 E832-E837. (doi:10.1152/ajpendo.00700.2009)

18 Tatosian DA, Guo Y, Schaeffer AK, Gaibu N, Popa S, Stoch A, Langdon RB \& Kauh EA. Dipeptidyl peptidase-4 inhibition in patients with type 2 diabetes treated with saxagliptin, sitagliptin, or vildagliptin. Diabetes Therapy 20134 431-442. (doi:10.1007/s13300-013-0045-8)

19 Herman GA, Bergman A, Stevens C, Kotey P, Yi B, Zhao P, Dietrich B, Golor G, Schrodter A, Keymeulen B et al. Effect of single oral doses of sitagliptin, a dipeptidyl peptidase- 4 inhibitor, on incretin and plasma glucose levels after an oral glucose tolerance test in patients with type 2 diabetes. Journal of Clinical Endocrinology and Metabolism 200691 4612-4619. (doi:10.1210/jc.2006-1009)

20 El-Ouaghlidi A, Rehring E, Holst JJ, Schweizer A, Foley J, Holmes D \& Nauck MA. The dipeptidyl peptidase 4 inhibitor vildagliptin does not accentuate glibenclamide-induced hypoglycemia but reduces glucose-induced glucagon-like peptide 1 and gastric inhibitory polypeptide secretion. Journal of Clinical Endocrinology and Metabolism 2007 92 4165-4171. (doi:10.1210/jc.2006-1932)

21 Migoya EM, Stevens CH, Bergman AJ, Luo WL, Lasseter KC, Dilzer SC, Davies MJ, Wagner JA \& Herman GA. Effect of moderate hepatic insufficiency on the pharmacokinetics of sitagliptin. Canadian Journal of Clinical Pharmacology 200916 e165-e170.

22 Deacon CF, Wamberg S, Bie P, Hughes TE \& Holst JJ. Preservation of active incretin hormones by inhibition of dipeptidyl peptidase IV suppresses meal-induced incretin secretion in dogs. Journal of Endocrinology 2002172 355-362. (doi:10.1677/joe.0.1720355) 
23 Migoya EM, Bergeron R, Miller JL, Snyder RN, Tanen M, Hilliard D, Weiss B, Larson P, Gutierrez M, Jiang G et al. Dipeptidyl peptidase-4 inhibitors administered in combination with metformin result in an additive increase in the plasma concentration of active GLP-1. Clinical Pharmacology and Therapeutics 201088 801-808. (doi:10.1038/clpt. 2010.184)

24 Hu P, Yin Q, Deckert F, Jiang J, Liu D, Kjems L, Dole WP \& He YL. Pharmacokinetics and pharmacodynamics of vildagliptin in healthy Chinese volunteers. Journal of Clinical Pharmacology 200949 39-49. (doi:10.1177/0091270008325152)

25 Bock G, Dalla Man C, Micheletto F, Basu R, Giesler PD, Laugen J, Deacon CF, Holst JJ, Toffolo G, Cobelli C et al. The effect of DPP-4 inhibition with sitagliptin on incretin secretion and on fasting and postprandial glucose turnover in subjects with impaired fasting glucose. Clinical Endocrinology 201073 189-196. (doi:10.1111/ j.1365-2265.2009.03764.x)

26 Rosenstock J, Foley JE, Rendell M, Landin-Olsson M, Holst JJ, Deacon CF, Rochotte E \& Baron MA. Effects of the dipeptidyl peptidaseIV inhibitor vildagliptin on incretin hormones, islet function, and postprandial glycemia in subjects with impaired glucose tolerance. Diabetes Care 200831 30-35. (doi:10.2337/dc07-1616)

27 Ohlsson L, Alsalim W, Carr RD, Tura A, Pacini G, Mari A \& Ahren B. Glucose-lowering effect of the DPP-4 inhibitor sitagliptin after glucose and non-glucose macronutrient ingestion in non-diabetic subjects. Diabetes, Obesity \& Metabolism 201315 531-537. (doi:10.1111/dom. 12062)

28 Aoki K, Masuda K, Miyazaki T, Togashi Y \& Terauchi Y. Effects of miglitol, sitagliptin or their combination on plasma glucose, insulin and incretin levels in non-diabetic men. Endocrine Journal 201057 667-672. (doi:10.1507/endocri.K10E-103)

29 Aoki K, Kamiyama H, Masuda K, Kamiko K, Noguchi Y, Tajima K \& Terauchi Y. Effects of miglitol, vildagliptin, or their combination on serum insulin and peptide YY levels and plasma glucose, cholecystokinin, ghrelin, and obestatin levels. Endocrine Journal 201461 249-256. (doi:10.1507/endocri.EJ13-0399)

$30 \mathrm{Wu}$ T, Ma J, Bound MJ, Checklin H, Deacon CF, Jones KL, Horowitz M \& Rayner CK. Effects of sitagliptin on glycemia, incretin hormones, and antropyloroduodenal motility in response to intraduodenal glucose infusion in healthy lean and obese humans, and patients with type 2 diabetes treated with or without metformin. Diabetes 2014. In press. (doi:10.2337/db13-1627)

31 Nauck MA, Heimesaat MM, Ørskov C, Holst JJ, Ebert R \& Creutzfeldt W. Preserved incretin activity of glucagon-like peptide 1 [7-36 amide] but not of synthetic human gastric inhibitory polypeptide in patients with type-2 diabetes mellitus. Journal of Clinical Investigation 199391 301-307. (doi:10.1172/JCI116186)

32 Hare KJ, Knop FK, Asmar M, Madsbad S, Deacon CF, Holst JJ \& Vilsboll T. Preserved inhibitory potency of GLP-1 on glucagon secretion in type 2 diabetes mellitus. Journal of Clinical Endocrinology and Metabolism 200994 4679-4687. (doi:10.1210/jc.2009-0921)

33 Christensen M, Vedtofte L, Holst JJ, Vilsboll T \& Knop FK. Glucose-dependent insulinotropic polypeptide: a bifunctional glucosedependent regulator of glucagon and insulin secretion in humans. Diabetes 201160 3103-3109. (doi:10.2337/db11-0979)

34 Vilsbøll T, Krarup T, Madsbad S \& Holst JJ. Both GLP-1 and GIP are insulinotropic at basal and postprandial glucose levels and contribute nearly equally to the incretin effect of a meal in healthy subjects. Regulatory Peptides 2003114 115-121. (doi:10.1016/S0167. 0115(03)00111-3)

35 Hansen L \& Holst JJ. The effects of duodenal peptides on glucagon-like peptide-1 secretion from the ileum. A duodeno-ileal loop? Regulatory Peptides 2002110 39-45. (doi:10.1016/S0167-0115(02)00157-X)

36 Moss CE, Marsh WJ, Parker HE, Ogunnowo-Bada E, Riches $\mathrm{CH}$, Habib AM, Evans ML, Gribble FM \& Reimann F. Somatostatin receptor 5 and cannabinoid receptor 1 activation inhibit secretion of glucosedependent insulinotropic polypeptide from intestinal $\mathrm{K}$ cells in rodents. Diabetologia 201255 3094-3103. (doi:10.1007/s00125-0122663-5)

37 Plamboeck A, Veedfald S, Deacon CF, Hartmann B, Wettergren A, Svendsen LB, Meisner S, Hovendal C, Vilsbøll T, Knop FK et al. The effect of exogenous GLP-1 on food intake is lost in male truncally vagotomized subjects with pyloroplasty. American Journal of Physiology. Gastrointestinal and Liver Physiology 2013304 G1117-G1127. (doi:10.1152/ajpgi.00035.2013)

Received 17 April 2014

Revised version received 9 June 2014

Accepted 16 June 2014 